\title{
O ensino de línguas na escola e a formação de leitores
}

\author{
Henry Daniel Lorencena Souza*
}

Resumo: O presente artigo faz um recorrido pela situação do ensino de línguas nas escolas, examinando as teorias que fundamentam os métodos de ensino atuais e como ressignificar o trabalho realizado em sala de aula. Além de atender as expectativas dos alunos, de obter uma competência comunicativa mais eficiente, a disciplina de Língua Estrangeira pode ter um papel fundamental na formação integral do aluno, desenvolvendo habilidades que o tornem autônomo no acesso a textos que contribuam para sua visão plural do mundo e dessa forma interagir em diferentes contextos culturais. Com essa visão, a inclusão da literatura e textos de diferentes gêneros nas aulas de Língua Espanhola pode contribuir para a formação de leitores, não só na L2, mas também na L1.

Palavras-chave: Ensino de línguas; Formação de leitores; Metodologia de ensino de L2.

Resumen: El presente artículo hace un recorrido por la situación de la enseñanza de lenguas en los colegios, examinando las teorías que fundamentan los métodos de enseñanza actuales y cómo resignificar el trabajo hecho en el aula. Además de atender a las expectativas de los alumnos, de obtener una competencia comunicativa más eficiente, la asignatura de Lengua Extranjera puede cumplir un rol fundamental en la formación integral del alumno, desarrollando habilidades que lo hagan autónomo en el acceso a textos que contribuyan para su visión plural del mundo

Professor de Língua Espanhola do Colégio de Aplicação/UFRGS. Formação em Comunicação Social e Letras. Mestre em Teoria da Literatura. E-mail: hdls@uol. com.br 
y de esa forma interactuar en distintos contextos culturales. Por ello, la inclusión de la literatura y textos de diferentes géneros en las clases de Español puede contribuir para la formación de lectores, no solo en la L2, sino también en la L1.

Palabras clave: Enseñanza de lenguas; Formación de lectores; Metodología de enseñanza de L2.

Nas últimas décadas, a ideia de um mundo globalizado tem transformado a opinião das pessoas sobre o ensino de línguas. Acreditar que o domínio de um segundo idioma pode ser um fator decisivo para que os estudantes ingressem no mercado de trabalho é algo consagrado na nossa sociedade. Mas junto a essa opinião generalizada encontramos outra, relacionada à escola, que identifica esse espaço como inapropriado para o ensino e aprendizagem de outras línguas.

$\mathrm{O}$ adjetivo que acompanha o nome de nossa disciplina já nos coloca numa posição diferenciada ao resto das matérias curriculares: estrangeira. Essa qualificação nos posiciona, na visão dos outros, como algo vindo de fora. Possivelmente essa ideia quase subliminar, aliada a conceitos difundidos e fundamentados dentro do ambiente escolar, tenha tornado o trabalho invisível, fazendo com que as demais disciplinas tratem de forma indiferente, quase desnecessária, a tarefa do professor de línguas. Atualmente, a criação de outros adjetivos que tentam alterar essa relação, pouco tem contribuído, pois não basta que a língua seja estrangeira ou adicional se o professor não cria condições que permitam que a escola seja um espaço de aprendizagem (processo consciente produzido pela instrução formal da língua como sistema) e de aquisição (processo espontâneo e inconsciente através do uso natural da língua com fins comunicativos).

Quando se fala da atualização da escola frente às tecnologias da informação, assimilando o desenvolvimento tecnológico para a educação, reconhece-se que é um caminho sem volta, pois as instituições devem, ou deveriam, acompanhar o progresso da sociedade. Com isso, as atenções têm caído sobre como os estudantes 
interagem com a tecnologia, a linguagem que desenvolvem ou o processamento das informações. Porém pouca atenção tem-se dado ao fato do papel que as línguas estrangeiras cumprem no acesso à informação, e como a escola pode facilitar o acesso ao mundo, criando espaços nos quais os estudantes desenvolvam sua competência comunicativa através do texto escrito.

A partir da Segunda Guerra Mundial, o ensino de línguas passou a sofrer mudanças significativas, podendo ser resumido nestas três etapas:

$1^{\mathrm{a}}$ - Enfoques tradicionais (até o final dos anos 60);

$2^{\mathrm{a}}$ - Ensino comunicativo clássico de línguas (de 1970 até 1990);

$3^{\mathrm{a}}$ - Ensino comunicativo moderno de línguas (vigente desde os anos 90).

Analisando esses três períodos, constata-se que a escola ficou, em muitos casos, presa ao passado, deixando de desenvolver metodologias de ensino suficientemente eficientes para atender as mudanças que o mundo enfrentou. Basta verificar quais eram os objetivos dos estudantes em cada uma das épocas referidas para perceber como os interesses atuais se diversificaram. Hoje, com o simples acionar de uma tecla de computador, o aluno tem acesso ao mundo, tendo a possibilidade de interagir em tempo real com falantes de diversas regiões.

Os enfoques tradicionais de ensino de línguas nas instituições escolares têm dado prioridade à competência gramatical, como se fosse a base para alcançar a competência linguística. Nesse sentido, muitos professores passaram a acreditar que apresentando regras gramaticais e estimulando a prática dessas regras o processo de aprendizagem ocorreria, centrando-se no acúmulo de um acervo de frases e modelos gramaticais. Entre os exercícios tradicionais desse modelo encontram-se a memorização de diálogos, a prática de perguntas e respostas, os exercícios de substituição de diferentes elementos orientados principalmente para a expressão escrita. 
A proliferação de cursos livres, aplicando ou desenvolvendo metodologias de ensino diferenciadas, pouco contribuiu para mudar a visão do ensino de línguas nas escolas. Embora a competência gramatical fosse necessária, o centro de atenção passava a ser o uso da linguagem de forma comunicativa. Era um conceito mais abrangente:

Envolve o conhecimento do que dizer e como dizer de forma adequada com base na situação, nos participantes, nos papéis que desempenham e nas suas intençôes. Os programas tradicionais de estudo da gramática e do vocabulário e os métodos de estudo não incluíam informações dessa natureza (RICHARDS, 2007, p. 15).

Os novos estudos apontavam para um enfoque (e não um método) que pretendia fazer da competência comunicativa o objetivo final do ensino de idiomas e desenvolver procedimentos para o ensino das quatro habilidades linguísticas (ouvir, falar, ler e escrever), a partir da independência entre a língua e a comunicação. Essa amplitude faz com que esse enfoque seja diferente quanto ao seu âmbito de aplicação e sua condição, pois não responde a nenhum texto específico ou a um único teórico; também não apresenta um modelo que possa ser aceito como definitivo.

Alguns pesquisadores acreditam que o Ensino Comunicativo da Língua supõe mais do que um ensino que integra o aspecto funcional com o gramatical. Richards \& Rodgers (1998) citam a noção de "competência comunicativa" de Hymes, em que a língua é comunicação e o seu desenvolvimento deve ser o objetivo do ensino. Chomsky acreditava que o fundamental da teoria linguística era caracterizar as habilidades abstratas dos falantes que lhes permitem produzir orações corretas do ponto de vista gramatical. Hymes afirmava que essa visão da linguística era estéril, pois a teoria deveria ser entendida como parte de uma teoria mais geral que incorporasse a comunicação e a cultura.

Outra teoria que defende o Ensino Comunicativo da Língua é a descrição funcional de Halliday (1975 apud RICHARDS; RODGERS, 1998). Suas teorias das funções da língua comple- 
mentam a teoria de Hymes sobre a competência comunicativa, apresentando uma sequência de funções básicas em sete níveis que o aluno deve desenvolver para conseguir uma autêntica competência comunicativa:

1. a função instrumental: empregar a língua para conseguir coisas;

2. a função reguladora: empregar a língua para controlar a conduta alheia;

3. a função interativa: empregar a língua para criar a interação com os outros;

4. a função pessoal: empregar a língua para expressar sentimentos e significados pessoais;

5. a função heurística: empregar a língua para aprender e descobrir;

6. a função imaginativa: empregar a língua para criar o mundo da imaginação;

7. a função representativa: empregar a língua para transmitir informações (HALLIDAY, 1975 apud RICHARDS; RODGERS, 1998, p. 73-74).

Outra análise, relacionando as teorias existentes sobre a competência comunicativa, é feita por Canale e Swain (1980 apud RICHARDS; RODGERS, 1998) na qual identificam quatro dimensões: a competência gramatical, a competência sociolinguística, a competência discursiva e a competência estratégica. A competência linguística corresponde ao domínio da capacidade gramatical e léxica; a competência sociolinguística se refere à compreensão do contexto social onde ocorre a comunicação, incluindo aqui os diferentes papéis sociais, a informação que partilham os participantes e a finalidade da interação. A competência discursiva se refere à interpretação dos elementos individuais da mensagem a partir de suas conexôes e como é representado o significado em relação com a totalidade do texto; e a competência estratégica se refere aos recursos que os participantes empregam para iniciar, terminar, manter, corrigir e retomar a comunicação.

No âmbito da teoria linguística, o Ensino Comunicativo da Língua tem uma base teórica muito rica, apesar de eclética. Richards e Rodgers (1998) resumem as principais características desse enfoque em quatro itens: 
a) A língua é um sistema para expressar o significado.

b) A função principal da língua é a interação e a comunicação.

c) A estrutura da língua reflete seus empregos funcionais e comunicativos.

d) As unidades fundamentais da língua não são apenas os elementos gramaticais e estruturais, mas as categorias de significado funcional e comunicativo que se manifestam nos discursos.

Sobre a aprendizagem em si, esse enfoque é compatível com as teorias de Johnson (1984) e Littlewood (1984), em que a aquisição da competência comunicativa em uma língua é um exemplo do desenvolvimento das habilidades que incluem tanto o aspecto cognitivo como o do comportamento:

$\mathrm{O}$ aspecto cognitivo inclui a interiorização de planos para criar comportamentos apropriados. Quanto ao emprego linguístico, estes planos derivam do sistema linguístico. Incluem regras gramaticais, procedimentos para a seleção de vocabulário e convençôes sociais que regulam a fala. $\mathrm{O}$ aspecto do comportamento inclui a automatização destes planos para que possam se transformar em realizaçóes fluidas em tempo real. Isto acontece principalmente por meio da prática, ao transformar os projetos em realizações. (LITTLEWOOD, 1984 apud RICHARDS; RODGERS, 1998, p. 76)

Essa teoria, como pode ser observada, dá importância à prática como meio de desenvolver as habilidades comunicativas. Finocchiaro e Brumfit (1983, apud RICHARDS; RODGERS, 1998) destacaram de forma esquemática as principais características práticas do Enfoque Comunicativo:

- O mais importante é o significado;

- Quando são empregados, os diálogos se centram nas funções comunicativas e normalmente não são memorizados;

- Apresentar os elementos da língua em um contexto é uma premissa fundamental; 
- Aprender uma língua significa aprender a se comunicar;

- Objetiva-se uma comunicação efetiva;

- A repetição pode ocorrer, mas de forma tangencial;

- Procura-se a pronúncia compreensiva, não a perfeição;

- É aceito qualquer recurso que possa ajudar o aluno, adaptados a sua idade, interesse, etc;

- As tentativas de comunicação são incentivadas desde o início;

- A língua materna pode ser empregada quando seja necessário, mas com moderação;

- A tradução pode ser empregada quando os alunos a precisarem ou possam tirar melhor proveito dela;

- Se for preciso, é possível começar com as leituras e a escrita já nos primeiros dias;

- O sistema da língua alvo será mais bem aprendido através da procura do estabelecimento da comunicação; - Objetiva-se a competência comunicativa (ou seja, a habilidade para empregar o sistema linguístico de forma efetiva e apropriada);

- A variação linguística é um conceito básico nos materiais e na metodologia;

- A sequência é determinada pela consideração do conteúdo, da função ou do significado que mantenha $o$ interesse;

- Os professores ajudam os alunos através de atividades que os motive a trabalhar com a língua;

- Cada aluno cria a língua, geralmente por meio do ensaio e do erro;

- O objetivo principal é a fluidez e o domínio aceitável da língua: a correção não é considerada como um aspecto abstrato, mas dentro de um contexto;

- Espera-se que os alunos se relacionem com outras pessoas, seja ao vivo (em trabalhos grupais) ou através da língua escrita. 
- O professor não sabe exatamente a língua que seus alunos vão empregar;

- A motivação intrínseca partirá do interesse por aquilo que está sendo comunicado na língua (FINOCCHIARO \& BRUMFIT, 1983 apud RICHARDS; RODGERS, 1998, p. 70-71).

Como forma de incluir esses conceitos à realidade do ensino de línguas nas escolas, atendendo também as necessidades de letramento dos estudantes, surge a literatura como motivação para a transformação nos processos de aprendizagem. Isso porque os textos podem colocar o aluno frente a situações reais de comunicação, nas quais terá que desenvolver estratégias para uma comunicação eficiente.

No caso específico do ensino de Espanhol para brasileiros, a literatura pode proporcionar benefícios que vão muito além da simples aquisição de vocabulário, pois a semelhança em termos estruturais com o português possibilita que o aluno construa novas concepções estéticas da escrita, estabelecendo uma comunicação real com o texto, permitindo-lhe, dessa forma, experimentar novas vivências dentro da cultura pertencente à língua que está aprendendo.

Os estudos sobre os processos de aquisição e aprendizagem de uma língua estrangeira sempre despertaram o interesse dos linguistas e dos educadores, mas, na grande maioria dos casos, a preocupação deles recaiu sobre a produção oral do aluno aprendiz.

Se a literatura não encontrou terreno fértil nesse campo, certamente foi devido à dificuldade de estudar os processos receptivos do aluno no ato de ler. Ao contrário da produção oral, que sim podia ser medida, e daí as teorias sobre "interlínguas", os processos receptivos somente podem ser interpretados de forma 
indireta. De acordo com Salaberri (1990), isso explica o fato de a compreensão da linguagem não ter sido analisada adequadamente. A pesquisadora espanhola destaca que é necessário considerar a compreensão como um processo que pode ser estudado dentro da psicologia cognitiva, tendo as seguintes características:

1. Na compreensão é tão importante rever as operações de decodificação de signos como os processos cognitivos que cabem;

2. A compreensão é um processo mental que requer a participação ativa do receptor na reconstrução do texto; 3. O leitor não leva em conta somente a frase que lê, mas tudo aquilo que já processou anteriormente e tenta prever o que vai acontecer. Por isso, não é a frase o centro de sua atenção, mas sim o texto em si;

4. Na compreensão processamos as mais variadas informações, não só as linguísticas, e vamos construindo nossos próprios esquemas conceituais;

5. Estes esquemas conceituais servem de guia no processo de compreensão. Pode-se falar de diferentes tipos de esquemas: espaciais, temporais, conhecimento de mundo, etc;

6. A inferência é fundamental para dar coerência ao texto, já que não toda informação é manifestada geralmente de forma explícita. (SALABERRI, 1990, p. 363)

Podemos deduzir, portanto, que a compreensão de um texto é um processo complexo que inclui a decodificação de informações, a construção de esquemas e o contraste entre a informação nova com aquela que o receptor já possuía.

Alguns estudos têm tentado determinar as características que definem um bom leitor. Desses estudos, Salaberri (1990) aponta que, do ponto de vista da compreensão, é possível afirmar que um leitor eficiente é aquele que: 
- Mantém na mente o sentido daquilo que leu;

- Lê frases extensas;

- Pula palavras ou frases de pouca importância;

- Procura o significado das palavras que desconhece através do contexto apresentado;

- Continua lendo, mesmo não entendendo uma palavra ou frase;

- Examina os desenhos e os elementos contextuais;

- Lê os títulos e constrói inferências dos mesmos;

- Emprega o conhecimento prévio que possui do mundo para fazer suas interpretações;

- Segue a leitura, propondo hipóteses que vai avaliando com o decorrer da leitura.

O leitor considerado pouco eficiente, ao contrário, seria aquele que:

- Tem o hábito de esquecer o significado da frase que leu;

- Lê palavra por palavra;

- Detém-se ao achar algo que não entende e não tem coragem de continuar;

- Não constrói hipóteses sobre aquilo que lê;

- Não transfere suas próprias experiências à leitura (Salaberri, 1990, p. 364).

As características apresentadas referem-se tanto a leitores de língua materna como de língua estrangeira. A partir dessas constatações, Salaberri cita as experiências no sentido de melhorar as estratégias dos maus leitores, fazendo-os conscientes do seu processo de leitura e orientando-os sobre possíveis melhorias. Os resultados foram satisfatórios, melhorando a auto-organização do leitor perante o texto.

Partindo dessa situação, destacou-se a necessidade de exercitar os alunos em três estratégias aplicáveis tanto na aula de língua materna como na de língua estrangeira: fazer inferências, 
fazer previsões sobre o que se lê, e desenvolver o hábito de ler de forma global e não palavra por palavra.

Não há evidências experimentais que possam indicar que quando se lê mal em uma língua estrangeira seja devido, exclusivamente, a deficiências existentes na língua materna, pois é necessário levar em conta o grau de competência linguística que o aluno possui. Alguns estudos demonstraram que alunos com níveis similares de competência na língua estrangeira apresentam diferenças na leitura por não terem as mesmas habilidades na língua materna (CLARKE, 1979 apud SALABERRI, 1990). Portanto, aqueles alunos que possuem um alto desenvolvimento de conhecimento conceitual na língua materna podem superar com maior facilidade as insuficiências nos níveis iniciais de aprendizagem de outra língua.

É possível afirmar que os processos de compreensão, em português e em espanhol, não apresentam diferenças significativas, já que colocam em jogo mecanismos universais. Wolff (1985 apud SALABERRI) menciona, por exemplo, que tanto os leitores em língua materna como os leitores em língua estrangeira fazem uso dos elementos contextuais para interpretar o texto: olhando as ilustrações e elaborando hipóteses sobre o texto que vai ler.

$\mathrm{Na}$ situação específica da língua estrangeira, o leitor não pode processar toda a informação linguística que lhe é oferecida, razão pela qual se vê obrigado a desenvolver estratégias adicionais de compreensão. Essas estratégias são baseadas principalmente na inferência, para poder dar coerência ao texto.

É possível afirmar, então, que são processos qualitativamente iguais, mas com diferentes níveis de realização, que exigem maior intensidade na língua estrangeira. Essa hipótese comprova a importância que a literatura pode ter no ensino de língua estrangeira, pois desenvolve habilidades que nenhum outro recurso didático pode substituir. 


\section{O texto e o leitor}

Tradicionalmente, nas aulas de língua estrangeira a atividade leitora tem sido dirigida no sentido do texto e não em direção ao leitor. Sendo a leitura uma atividade cognitiva na qual se produz uma relação estreita entre o texto e a experiência prévia do aluno, torna-se imperativo colocar a leitura no sentido do leitor.

O significado de um texto não se limita apenas ao que está impresso na página. Os textos não são totalmente explícitos e por isso devem ser completados pelo leitor. Cabem aqui os princípios apontados pela estética da recepção, em que Iser (1979) retoma e amplia a formulação das estruturas centrais de indeterminação no texto, destacando seus vazios e suas negações. Tal dupla característica da estrutura textual provoca, no leitor, a necessidade da contínua formação de uma "figura de relevância", de um tema e seu contorno no horizonte, e a não menos contínua transformação noutras figuras de relevância.

Do ponto de vista cognitivo, Anderson (1978 apud SALABERRI, 1990) apontou para os "squemata", chamando assim as estruturas cognitivas abstratas que incorporam o conhecimento generalizado sobre os objetos e os conhecimentos. São eles os responsáveis por preencher os vazios que ficam na leitura de um texto, permitindo que o leitor faça uma leitura coerente através da elaboração de inferências. De acordo com os esquemas de cada leitor, são produzidas diferentes interpretações de um mesmo texto, que podem ser também diferentes das do autor.

As teorias antes apresentadas destacam a importância de, ao trabalhar a literatura na aula de língua estrangeira, realizar atividades de pré-leitura no sentido de proporcionar ao aluno os conhecimentos linguísticos e culturais necessários para um melhor aproveitamento do texto, sem que o professor interfira na sua interpretação. Essa preparação para a leitura é fundamental, pois dela depende o estímulo para que o aluno construa o seu conhecimento. $\mathrm{Na}$ vida real são vários os propósitos que nos 
conduzem à leitura, e também na aula é necessário promover atividades e leituras que estejam de acordo aos interesses dos alunos.

\section{Considerações finais}

No que se refere ao ensino da língua estrangeira, o parágrafo $5^{\circ}$ do artigo 26 da LDB (Lei de Diretrizes e Bases), de 20 de dezembro de 1996, estabelece que sua inclusão no currículo será na parte diversificada, sendo obrigatória a partir da $5^{\text {a }}$ série.

A novidade da lei foi a de estabelecer "[...] pelo menos uma língua estrangeira moderna, cuja escolha ficará a cargo da comunidade escolar, dentro das possibilidades da instituição $[\ldots]$ ", medida que abriu as portas das escolas ao ensino de outras línguas.

A partir do que a LDB estabelece, as Diretrizes Curriculares Nacionais para o Ensino Médio passaram por uma reavaliação, fazendo com que o ensino da língua estrangeira ganhasse um novo enfoque. As DCNEM, no art. $4^{\circ}$, determinam que, "[...] além da língua portuguesa, os alunos devem ter competência nas línguas estrangeiras e outras linguagens contemporâneas como instrumentos de comunicação e como processos de constituição de conhecimento e de exercício de cidadania". No artigo 10 o ensino da língua estrangeira também é abordado, estabelecendo que "[...] o conhecimento e o uso da língua estrangeira moderna deve servir como instrumento para o acesso a informações e a outras culturas e grupos sociais".

Analisando o que os artigos propõem, conclui-se que, para tornar verdadeiro o que o papel pressupóe, é necessário uma competência comunicativa bastante ampla numa língua estrangeira, algo difícil de adquirir no ensino escolar tradicional, já que a literatura não encontra espaço e os professores se limitam a atividades tradicionais de caráter estrutural .

Ao excluir a literatura da aula de língua estrangeira, o professor está privando o seu aluno de manter um contato autêntico e 
real com a língua que está aprendendo, o que permitiria situações de aquisição. Trabalhar com o texto literário não significa realizar as ultrapassadas atividades de tradução ou de catar as dificuldades estruturais que o texto possa apresentar. É preciso explorar aquilo que o enfoque comunicativo tem de inovador e que o torna eficiente na aula de língua: a comunicação.

Quando acreditamos que o leitor é capaz de estabelecer um diálogo com o texto, em que é possível haver uma troca de experiências e vivências, reconhecemos também a possibilidade única que a literatura pode proporcionar, pois podemos oferecer ao aluno uma verdadeira imersão na cultura da língua. Dessa forma, o aluno não estará ampliando sua competência linguística, mas também estará abrindo novos horizontes de possibilidades, conhecendo realidades distantes da sua e aumentando sua visão de mundo.

Para finalizar, destacamos a importância de promover ações integradas da Língua Estrangeira com a Língua Portuguesa e a Literatura, pois não é possível esperar que um aluno seja leitor em outro idioma se não o for na sua própria língua.

\section{Referências}

JAUSS, Hans Robert et al. A literatura e o leitor: textos de Estética da Recepção. São Paulo: Paz e Terra, 2001.

LDB, Lei de Diretrizes e Bases. Disponível em: http://pt.scribd.com/ doc/19690886/LDB-ATUALIZADA. Acesso em 23 de abr. 2011.

MARTÍNEZ, A. Lázaro; SALABERRI, M. del Sagrario. Sobre didáctica de la lengua y la literatura. Madrid: Publicaciones Pablo Montesino, 1990.

RICHARDS, Jack; RODGERS, Theodore. Enfoques y métodos en la enseñanza de idiomas. Madrid: Cambridge, 1998.

RICHARDS, Jack. La enseñanza comunicativa de Lenguas Extranjeras. São Paulo: SBS, 2007. 